\title{
Identification of physical and geochemical controls on the electrokinetic in-situ leaching of gold
}

\author{
PABlo ORTEGA-TONG ${ }^{1,2}$, JAMES JAMIESON ${ }^{1,2}$, \\ RICCARDO SPROCATI ${ }^{3}$, JING SUN ${ }^{4}$, MASSIMO ROLLE $^{3}$, \\ ANDY FOURIE ${ }^{5}$, HENNING PROMMER ${ }^{1,2^{*}}$ \\ ${ }^{1}$ School of Earth Sciences, UWA, Crawley, WA 6009, \\ Australia (*Henning.Prommer@csiro.au) \\ ${ }^{2}$ CSIRO Land and Water, Floreat, WA, Australia \\ ${ }^{3}$ Department of Environmental Engineering, DTU, 2800 \\ Lyngby, Denmark. \\ ${ }^{4}$ Institute of Geochemistry, Chinese Academy of Sciences, \\ Guiyang 550081, China. \\ ${ }^{5}$ School of Civil, Environmental and Mining Engineering, \\ UWA, Crawley, WA 6009, Australia
}

An increasing demand for base metals, declining grades in newly discovered ore bodies and environmnetal concerns are all important drivers for the devlopment of alternative minining technologies. For example, in situ leaching (ISL) has a significantly smaller environmental footprint compared to conventional mining techniques as it avoids the detrimental impacts of hauling large volumes of overburden. However, limited by the often low hydraulic conductivity of many ore bodies, ISL applications over the last decades have been largely limited to the recovery of uranium. Recently, electrokinetic in-situ leaching (EK-ISL) was proposed as a novel variant of ISL, where the application of an electric field is used to induce the (electro)migration of lixiviants and for the recovery of gold. Centimetre-scale experiments conducted on gold-bearing synthetic and intact ore samples using iodide/triiodide as a lixiviant revealed the in-principle feasibility of the technology $[1,2]$. For an in-depth analysis of the experimental results we now use in the present study a reactive transport modelling approach for a closer inspection of the details of the ionic transport behaviour and of the geochemical processes that control gold recovery efficiency during EK-ISL. In the applied numerical model [3] electrokinetic transport phenomena controlling lixiviant and gold migration are considered through the application of the Nernst-Planck equation, in conjunction with a full suite of geochemical reaction capabilities. Subsequently, we use the lab-derived model to further explore the feasibility and controls on EK-ISL recovery efficiency under physically and geochemically heterogeneous and under varying voltage gradient conditions at the field-scale.

[1] Martens et al., (2018a) Hydrometallurgy, 178,124-136 [2] Martens et al., (2018b) Hydrometallurgy, 175, 70-78.

[3] Sprocati et al (2019) Adv. Water Resour. 127, 134-147. 